\title{
GESTÃO COMUNICACIONAL DE CRISES E IMAGEM CORPORATIVA: Uma relação de interferências na realidade da organização adventista ${ }^{1}$
}

\author{
Felipe Diemer de Lemos $^{2}$ \\ Robson Dias ${ }^{3}$ \\ Victor Márcio Laus Reis Gomes ${ }^{4}$ \\ Luiz Carlos de Assis Iasbeck ${ }^{5}$
}

\begin{abstract}
Resumo: Discute a importância da gestão profissional de crises com repercussão comunicacional, na medida em que essas crises fazem parte do cotidiano das organizações de um modo geral, inclusive estão presentes na realidade da Igreja Adventista do Sétimo Dia no Brasil. Essas crises interferem na forma como os públicos enxergam e formam sua percepção de uma determinada organização e podem se constituir em elementos capazes de afetar a imagem corporativa. A proposta é estabelecer, por isso, uma relação entre o que essas crises representam para a própria imagem da organização em termos de impacto e influência, avaliando qual seria a relevância de se geri-las adequadamente sob o ponto de vista comunicacional. Por meio de pesquisa exploratória e qualitativa, além de conceituar as crises de imagem na organização, inclusive como algo inerente a qualquer tipo de organização, vamos discutir o conceito de imagem corporativa da organização a partir de um olhar sobre os estudos teóricos voltados à reflexão de imagem no contexto da semiótica da cultura e suas diferentes implicações, especialmente estratégicas para uma organização.
\end{abstract}

Palavras-chave: Comunicação organizacional; Imagem Corporativa; Crises de Imagem; Igreja Adventista.

Abstract: Discusses the importance of professional crisis management with communicational repercussions, as these crises are part of the daily life of organizations in general, and are present in the reality of the Seventh-day Adventist Church in Brazil. These crises interfere with the way audiences see and form their perception of a particular organization and can constitute elements that can affect the corporate image. The proposal is to establish, therefore, a relationship between what these crises represent for the organization's own image in terms of impact and influence, evaluating the relevance of managing them adequately from a communicational point of view. Through exploratory and qualitative research, in addition to conceptualizing image crises in the organization, including as something inherent in any type of organization, we will discuss the concept of

\footnotetext{
${ }^{1}$ Trabalho apresentado no I Congresso Adventista Latino-Americano de Pesquisadores da Comunicação (Adventcom), realizado em Engenheiro Coelho, SP, entre os dias 12-14 de setembro de 2017. Evento institucional pioneiro dessa confissão e totalmente voltado para a Comunicação.

${ }^{2}$ Jornalista pela Universidade do Sul de Santa Catarina (UNISUL) e especialista em Comunicação Corporativa (UNISUL) e Marketing Estratégico (Centro Universitário Adventista de São Paulo - UNASP). Mestrando em Comunicação - Universidade Católica de Brasília (PPGCOM/UCB), linha Processos Comunicacionais nas Organizações. Assessor de Comunicação da Divisão Sul-Americana da Igreja Adventista do Sétimo Dia (DAS Brasil).

${ }^{3}$ Jornalista, mestre e doutor em Comunicação. Professor e pesquisador do mestrado em Comunicação da Universidade Católica de Brasília (PPGSSCOM/UCB), linha Processos Comunicacionais nas Organizações. Líder do grupo Prêmios, Indicadores e Estratégias em Comunicação.

${ }^{4}$ Publicitário, mestre em Administração e doutor em Comunicação. Professor e pesquisador do PPGSSCOM/UCB, linha Processos Comunicacionais nas Organizações. Líder do grupo de pesquisa: Núcleo de Estudos Comunicacionais da Estratégia (ESTRACOM). Líder do projeto de pesquisa O noticiário de negócios e os discursos sobre a estratégia em grandes empresas privadas do Distrito Federal - FAPDF - 193.001.037/2015 Projeto Externo.

${ }^{5}$ Possui graduação em Comunicação Social, habilitação em jornalismo, pela Universidade Federal de Juiz de Fora (1975), mestrado em Comunicação e Semiótica pela Pontifícia Universidade Católica de São Paulo (1993) e doutorado em Comunicação e Semiótica pela Pontifícia Universidade Católica de São Paulo (1997). Atualmente é professor titular no Programa de Pós-Graduação, Mestrado em Comunicação, da Universidade Católica de Brasília (UCB), na linha de pesquisa Comunicação Organizacional, professor de cursos de pósgraduação lato-sensu em Comunicação Organizacional, Assessorias de Comunicação e Ouvidoria e coordenador do Grupo de Pesquisa em Ouvidoria pelo CNPq.
} 
corporate image of the organization from a look at the theoretical studies focused on the reflection of image in the context of culture semiotics and its different implications, especially strategic for an organization.

Keywords: Organizational communication; Corporative image; Image Crisis; Adventist Church.

\section{Crises de imagem em três ângulos: evento, percepção e construção de credibilidade}

As organizações, de maneira geral, convivem em seu cotidiano com situações de tensão. E muitas dessas tensões podem efetivamente se tornar, em dado momento e circunstância, em situações de crise. O conceito de crise, defendido por estudiosos do assunto, é bastante amplo e abarca muitos aspectos relacionados, tanto à organização quanto aos públicos ligados a ela.

Para nossa análise, procuramos fazer um recorte nessa grande variedade conceitual, entendendo as crises de imagem organizacional a partir de alguns pontos de vista. Basicamente são três ângulos que propomos para se enxergá-las e que levamos em consideração nesse artigo, na relação com imagem corporativa. Esses ângulos não são causas das crises, mas expressões da mesma, ou seja, consequência de uma relação discrepante entre o discurso organizacional e a imagem percebida.

O primeiro ângulo é o da crise de imagem organizacional enquanto um evento específico capaz de criar algum tipo de incômodo e abalo para a organização de maneira geral e que difere, portanto, de risco ou emergências. Essa primeira visão é a de crise como

Um evento específico e inesperado, que cria altos níveis de incerteza e ameaça às empresas e aos seus públicos e gera grande pressão por respostas imediatas sobre as suas causas, seus efeitos e consequências. (NETO, 2010, p.187).

O que se pode apreender desse conceito é um primeiro aspecto de definição de crise como uma situação com repercussão junto a públicos diversos (portanto, de conhecimento público) e que efetivamente não se deu de forma totalmente previsível. Embora possa ter sua origem em questões internas da organização, a crise é um evento inesperado, ou seja, estava fora dos planejamentos e, portanto, não foi elencada especificamente como uma variável a ser considerada nas estratégias, sendo diferente, por isso, do risco na medida em que esse geralmente é "uma ameaça latente a um indivíduo ou organização, é um perigo sem controle, que pode se tornar concreto a qualquer momento" (TEIXEIRA, 2013, p. 26). Aliás, monitorar pontos de vulnerabilidade e ameaças é justamente o que alguns especialistas chamam de gestão de risco. "É a antecipação do que pode acontecer, pensando tudo o que pode dar 
errado. A gestão da crise contemplaria as ações quando a crise já está instalada" (FORNI, 2007, p. 210).

Um segundo aspecto, que consideramos essencial e que permeia nossa análise e discussão nesse artigo, é o de se encarar ou enxergar as crises de imagem pelo prisma da percepção dos públicos. Nesse caso, o evento inesperado precisa ser, também, percebido como tal para que consista, em última instância, em crise. A crise, nesse contexto, pode significar uma ameaça às expectativas idealizadas pelos públicos que lidam de alguma maneira e em algum nível com a organização (também conhecidos como stakeholders), porque eles assim o percebem (COOMBS, 2007, p. 41).

\begin{abstract}
Desta definição deduz-se que uma crise é perceptual. Ou seja, não é o evento em si que é uma crise, mas é a nossa percepção desse evento que nos ajuda a classificá-lo como tal. Assim, podemos ainda diferenciar o que é um fenómeno de crise do que é uma crise, sendo o primeiro um acontecimento que rompe com o estado normal de desenvolvimentos e desperta um conjunto de reacções, e o segundo uma realidade situacional em que os agentes envolvidos sofrem as consequências que daí resultam. (JORGE, 2010, p. 41).
\end{abstract}

Uma terceira maneira de enxergar as crises, que definimos para essa análise, leva em conta, também, o aspecto da credibilidade. As crises se caracterizam por uma certa desorganização, uma espécie de caos no sistema organizacional e evidentemente esse tipo de ruptura com o previsível e com o planejado implica abalos para um bem intangível, mas de importância para uma discussão posterior de imagem corporativa que é a credibilidade. Em postulados sobre o que alguns estudiosos como Wilson Bueno chamam de "teoria das crises", há fatores úteis para a discussão a que nos propomos e um deles é justamente o fato de a credibilidade de uma pessoa ou organização ser colocada em xeque com as crises.

[...] a crise, qualquer que seja ela, traz sempre embutida a capacidade (que não deve ser jamais desprezada) de abalar seriamente a credibilidade da empresa. A crise tem, no seu DNA, o vírus da desorganização, do pânico, do escândalo, e ele pode contaminar rapidamente todo o organismo. Logo, a crise deve ser enfrentada com vigor. (BUENO, 2009, p.141).

\title{
Imagem corporativa (percepções)
}

Após selecionar algumas definições que ajudam a caracterizar a crise de imagem, efetivamente procuremos compreender o que, para efeitos de elaboração desse artigo, pode vir a ser a imagem corporativa. Parte-se da ideia de imagem não como algo unicamente 
produzido por alguém (ou uma organização) no seu discurso, porém que recebe forte influência de quem a percebe, ou seja, o receptor de um determinando discurso e, assim, em última instância, os públicos com quem uma determinada organização se relaciona de alguma forma. Temos, então, um princípio inicial de que a imagem vem, também, a partir da percepção. Seriam as imagens mentais, como os sonhos, as lembranças e as próprias ideias muito conectadas com as informações obtidas de forma perceptual (IASBECK, 1997, p. 73).

Utilizamos aqui o conceito de imagem da semiótica perciana associado à ideia de símbolo. Nesse caso, o signo (aquilo que representa algo para alguém), na relação com o seu objeto (o que efetivamente é representado pelo signo), acaba percebido em diferentes níveis de relacionamento. Por esse pensamento, pelo menos três possíveis tipos de relacionamento surgem e que dão origem aos conceitos de ícone, índice e símbolo. Para esse artigo, compreendemos que o que mais se adequa à ideia de imagem corporativa é a relação de signo e objeto na condição de símbolo. O signo, nesse caso, refere-se ao objeto em uma relação que leva em conta o viés normativo e uma associação de ideias gerais (PEIRCE, 2005, p. 52,53).

O símbolo, em Pierce, é a dimensão do hábito, da lei, das normas, das regularidades. Ele representa o seu objeto pela arbitrariedade das convenções, e pode ser assim compartilhado por seus interpretantes nas relações culturais. (IABECK, 1997, p. 79).

A percepção do signo, por esse ponto de vista, tem muito a ver com a maneira como ocorre com os intérpretes em um tipo de relação influenciada por questões culturais (daí a importância dos estudos da Semiótica da Cultura). O intérprete (no caso, o público-alvo) sempre tem a possibilidade de dar uma nova percepção ao signo, ou, se preferirmos dizer, emprestar um significado novo por conta das suas experiências de vida e memória e isso se dá o tempo inteiro nas relações humanas.

A semiótica perciana admite possibilidades de interpretantes do signo. A imediata e a dinâmica, principalmente. O interpretante imediato tem a ver com o que o signo está apto a produzir na mente de quem está interpretando. Não é o que o signo efetivamente produz, mas o que ele pode produzir. É o que já vem junto com o signo. Se falamos de um elefante, é impossível inicialmente não se pensar no animal típico da África quando se ouve essa expressão. Aí não temos, ainda, o elemento da subjetividade do público. (SANTAELLA, 1985, p. 13).

No caso do interpretante dinâmico, aí já temos a possibilidade de o signo exercer a já citada ação de dar um novo significado ao signo. 
Daí decorre o interpretante dinâmico, isto é, aquilo que o signo efetivamente produz na sua, na minha mente, em cada mente singular. E isso ele produzirá dependendo da sua natureza de signo e do seu potencial como signo. (SANTAELLA, 1985, p. 13).

Além disso, como é importante frisar, que a formação da imagem, como já mencionado no início desse capítulo, recebe grande influência da elaboração do discurso da organização. Essa, também, é uma forma de contribuir para compor a imagem na mente dos públicos a quem se destinam as mensagens de uma organização. Nesse caso, considera-se o discurso como a organização e produção de informação em linguagens para explicitar e caracterizar não apenas intenções, mas crenças e convicções. (IASBECK, 2007, p. 88).

A partir desse ponto, enfatizamos a nossa ideia de imagem também construída por essa percepção que é, na verdade, um processo constante de diálogo entre as concepções de mundo que as pessoas possuem e a forma como enxergam os signos e aquilo que chega até elas inclusive por meio do esforço comunicacional das organizações (discurso) e, assim, temse um produto que podemos chamar de imagem corporativa perceptual.

Essa imagem - seja da empresa, de produto, de marca - é desenhada na mente do consumidor com base em atributos desejáveis ou rejeitáveis, pautados em valores considerados caros às comunidades nas quais as empresas atuam. (IABECK, 1997, p. 80).

É bastante interessante o conceito de imagem mental percebida e que, nesse sentido, reforça a ideia de algo desenhado ou construído efetivamente na mente (ou cabeça) do consumidor, do público-alvo, dos públicos de interesse, dos receptores, ou seja como se quiser referir a quem interage com os signos. Essa imagem mental é, em última instância, preponderante para o estabelecimento da imagem corporativa. No caso de uma organização como uma empresa ou uma igreja, a imagem mental pode ser constituída por diferentes elementos que vão desde as induções, deduções, as percepções de quem vê e das próprias experiências dos indivíduos que fazem parte dessa organização. É a associação de tudo isso que ajuda a compor essa imagem e isso está muito relacionado com o que está, como diz um teórico, na "cabeça das pessoas" (COSTA, 2009, p. 53).

Por isso, destaca-se o valor da interação e de tudo o que pode contribuir para essa interação entre organização e públicos ou romper de alguma forma no sentido de formação da imagem corporativa. 
Depois de interagir com uma organização, os públicos podem ter uma imagem diferenciada da que tinham antes. Se isso acontecer, o objetivo é de que a imagem seja melhor, e não pior. (ARGENTI, 2011, p. 99).

A interação tem efeito direto sobre a formação dessa imagem e, a longo prazo, poderá impactar sobre o que se conhece como reputação. Pode-se entender reputação como um processo mais duradouro, ao longo de um tempo maior, em que a imagem de uma organização possa ser consolidada. É determinada, então, pelas percepções que se tem acerca da organização e fruto, por isso, também da interação (THOMAZ \& BRITO, 2007).

Mas o que pode afetar a interação de uma organização, a exemplo da Igreja Adventista do Sétimo Dia, para que sua imagem perante os públicos e, em última instância, até mesmo sua reputação, possam sofrer alterações? As crises de imagem poderiam ser esse tipo de interferência e, se são, o que pode ser feito para agir em relação a isso?

\section{Interação e interferência na formação da imagem: caso Igreja Adventista do Sétimo Dia}

Como já vimos, um dos aspectos das crises de imagem é o seu elemento perceptual, ou seja, também estão dentro do plano de percepção dos públicos. Só que, ao mesmo tempo em que se apresentam como elementos de percepção, as crises de imagem podem ser compreendidas, ainda, como interferências no processo de construção ou formação da imagem de uma organização. Vão, por isso, muito além da ideia de simplesmente um obstáculo a ser superado pela organização como um incômodo pontual, isolado. As crises de imagem, enquanto elementos percebidos pelos públicos com os quais a organização lida, têm o potencial de nortear como se vê certa organização.

A organização adventista, aqui em análise a Igreja Adventista do Sétimo Dia no Brasil com seus mais de 15 mil templos, instituições educacionais, de saúde e ação humanitária, pode ser considerada uma organização a exemplo de outras empresas. Possui atuação junto não apenas a seus fiéis e membros (que se constituiriam em um tipo de público), mas, por sua própria concepção de missão, tem interesse em atuar ou interagir com outros públicos que não meramente os que já aderiram a sua organização formalmente. Na sua declaração de missão, a Igreja afirma que o que a impulsiona, enquanto organização, é 
servi-Lo como Senhor e preparando-as para Sua breve volta". É, portanto, uma organização que deseja e efetivamente interage com outros públicos e isso a coloca na perspectiva de entender que sua imagem também está sendo formada por esses públicos permanentemente (IASDCENTRALDEBRASÍLIA, 2017).

Nesse ponto, é possível se começar a pensar em crises de imagem como elementos que, por também serem perceptuais, deverão, de algum modo, ser objeto de algum tipo de gestão ou gerenciamento. Em março de 2007, por exemplo, a organização adventista foi abalada com a morte de uma criança com idade de 1 ano e meio encontrada morta dentro de um tanque batismal de uma congregação local. O tanque é o espaço onde habitualmente a organização realiza cerimônias de expressão pública da admissão de novos fiéis, os batismos. O episódio teve repercussão nacional, especialmente nos meios de comunicação e, ainda que nenhum membro da denominação fosse formalmente acusado pela morte da criança, houve suspeitas de negligência. Dez anos depois, reportagem da mídia local afirma que "a família chegou a acionar judicialmente a Igreja Adventista do Sétimo Dia, por negligência, mas entrou em um acordo com a instituição".

Nesse episódio, é possível inferir que a percepção da família e de muitas pessoas que tiveram contato com as informações veiculadas pelos meios de comunicação acerca do episódio pode ter sofrido alteração pela veiculação da crise que, no caso citado, criou uma desordem na organização adventista, com consequências não apenas em âmbito local, mas em nível nacional.

Há, então, o fato gerador da crise e a percepção dessa crise a partir da visibilidade que o episódio ganha. Levando em conta que atualmente a percepção não se restringe ao que é divulgado nos meios de comunicação convencionais, mas com forte influência da veiculação por meio de perfis de indivíduos nas chamadas mídias sociais, a interação, no universo digital, adquire um peso maior.

Outro fator relevante é a interação estabelecida nas redes sociais...estabelecer corretamente uma relação com seus públicos de interesse pela internet também faz parte da identidade corporativa, pois cada aproximação feita pode estreitar ou não a confiança (TEIXEIRA, 2013, p. 52).

A noção de público, de forma alguma, restringe-se às pessoas que unicamente entram em contato ou são expostas a informações veiculadas por meio dos veículos tradicionais de comunicação (TV, rádio, portais de internet, revistas, jornais). Todas as pessoas que, de alguma maneira, interagem com a marca adventista nas mídias sociais se constituem públicos 
interessados ou de interesse e que, de alguma maneira, exercerão certa influência sobre como essa marca será percebida, como efetivamente será desenvolvida sua imagem corporativa.

\section{Gerenciamento de crises de imagem: operação-abafa ou reconfiguração de imagem?}

Dialogamos sobre como podem ser vistas as crises, sua interferência e influência sobre o que entendemos que seja a imagem corporativa de uma organização e, inclusive, tomamos rapidamente o caso da Igreja Adventista, como exemplo de uma organização com diversos e diferentes públicos associados a ela.

Uma organização religiosa, como a Igreja Adventista, que apresenta conceitos claros de serviço à sociedade e, pelo fato de expor em seu discurso a missão de levar uma mensagem de esperança às pessoas, tem distintos públicos formadores da sua imagem e, em suas crises, corre riscos de ter abalos em sua imagem e, dependendo da forma como isso for gerenciado, até de sua reputação. E afetar a reputação significa, no caso de uma organização com viés eminentemente religioso, colocá-la em situação de profunda vulnerabilidade e ameaça a passivos caros como a credibilidade e a confiabilidade.

O gerenciamento da crise de imagem, por isso, precisa ser observado de uma forma mais ampla. O trabalho de gestão pode evidenciar, em primeiro lugar, que a organização não está imune a ameaças e suscetibilidades e que o gerenciamento se insere no contexto de vulnerabilidade, o que não significa necessariamente fracasso. "Saber-se vulnerável é o primeiro passo para uma visão mais realista sobre a importância estratégica da gestão de riscos e do gerenciamento de crise". (LUCAS, 2007, p.58).

O gerenciamento de crises precisa ser encarado, na ótica de alguns autores, como não simplesmente uma ameaça, algo a ser, usando o jargão corporativo, "abafado" como se estabelecido que se trate apenas de um episódio inoportuno que afetou a normalidade organizacional. Por essa razão, inclusive recomendam o preparo adequado para o manejo com as crises de imagem, já que, por trás dessa gestão, está a própria reconstrução da imagem corporativa, que em etapas posteriores pode conduzir a mudanças de comportamento, a alterações da própria forma de ser da organização.

Esta preparação é inerente à forma como as organizações veem a mudança e encaram as crises: como ameaças à actividade organizacional, ou como oportunidades de aprendizagem antes, durante e depois da crise (cf. Cunha, 2006).

Enquanto a primeira é inerente às organizações mais burocráticas, que não veem a 
mudança de forma natural e que têm mais dificuldades em aprender com os erros, acabando por repetir o seu comportamento, mesmo quando este se torna disfuncional e ele próprio capaz de gerar crises e dificultar a sua resolução, na segunda, a organização aprende quando reflecte criticamente e altera o seu comportamento de forma a evitar ou a memorizar problemas (JORGE, 2010, p.46).

Pode-se compreender que a "operação-abafa", caracterização tipicamente associada à atividade de gestão de crises de imagem, não parece ser o que essencialmente se propõe a ser essa atividade, especialmente quando se olha para uma organização como a Igreja Adventista que precisa, pela própria natureza de sua atividade, zelar por essa imagem corporativa perante fiéis e outros públicos. Ou seja, a organização é vista, da parte dos seus públicos, segundo a abordagem da imagem corporativa como algo decorrente de percepção e das próprias crises como elementos perceptuais.

Gerir as crises de imagem é, assim, gerir, de certa forma, a própria imagem corporativa da organização porque o que está implicado ali é muito mais do que um fato negativo que momentaneamente preocupa a organização e requer obviamente uma reação dentro de protocolos previamente estabelecidos. Na gestão das crises de imagem, há implicações concretas para a forma como a organização é percebida.

\section{Considerações finais}

A partir da constatação de uma imbricada relação entre crise de imagem e formação da imagem corporativa de uma organização, pelo menos duas considerações preliminares podem ser apresentadas aqui a partir do exposto e do que ainda se estuda nessa relação.

A primeira consideração diz respeito ao fato de que a atividade de gestão das atividades de gerenciamento de crises de imagem, sob o ponto de vista comunicacional, se mostra altamente recomendável, especialmente no caso de uma organização religiosa como a Igreja Adventista do Sétimo Dia, na medida em que as crises podem ter efeitos específicos sobre a imagem corporativa da Igreja Adventista em nível de percepção dos públicos e, em casos extremos, até abalos para a reputação.

O fato de ser uma organização eminentemente com fins religiosos compele, de certa maneira, a Igreja Adventista do Sétimo Dia a exercer uma maior preocupação com a maneira como é vista por seus fiéis e mesmo por simpatizantes. Isso se dá na medida em que sua credibilidade parece ser muito menos avaliada por conta do lançamento de produtos, projetos ou programas e muito mais por aquilo que ela representa no imaginário de quem a observa, 
tanto os que estão dentro de sua organização quanto aqueles que estão fora. Nesse caso, a reputação se torna um bem não mais opcional, mas absolutamente necessário para que a organização consiga, inclusive, alcançar suas metas.

Além disso, fugindo um pouco do que normalmente se estuda nesse caso, ou seja, instituições públicas ou corporações comerciais, igrejas protestantes ou religiões em geral passam a ter uma estrutura com um nível tal de complexidade e tamanho que é possível se começar a falar no gerenciamento profissional de crises de imagem como área de interesse dessas organizações. A interação crescente no mundo digital e, por consequência, uma ampla exposição nesse ambiente sem que se possa frear isso de alguma forma, também emergem como fatores que podem despertar nesse tipo de organização religiosa o interesse maior por uma gestão profissional de crises.

Chama a atenção, nesse contexto, parte do resultado de uma pesquisa chamada The company behind the Brand II: In Goodness We Trust, realizada pela Weber Shandwick com a KRC Research com 2.100 consumidores e 1.050 executivos seniores em 21 mercados mundiais específicos. Embora evidentemente o foco sejam corporações comerciais, um dado se mostra bastante significativo para nortear ações de outras organizações. Uma das perguntas o seguinte: Quando você quer aprender mais sobre alguma companhia, o que é mais importante?

Entre as respostas, o resultado mostrou que, para $88 \%$ dos que responderam, o que mais importava era o que os consumidores diziam sobre a companhia. Já para $85 \%$ o que mais importava era como a companhia reagia ou respondia diante de um problema (situação de crise). Muito provavelmente uma situação muito mais perceptual do que se pode pensar e que, de acordo com esse levantamento, influi na forma como o público vê a própria organização.

A outra consideração a ser colocada, até em forma de questionamento, é a seguinte: Será que podemos falar em gestão de crise como uma atividade meramente técnicoadministrativa ou de cunho eminentemente jurídico-legal? Ou seja, o trabalho estratégico de gerenciar a forma como as crises podem ser percebidas e o impacto disso para a consolidação da imagem da organização perante seus públicos pode se restringir a essas áreas ou há, por um outro lado, uma necessária interferência dos estudos de comunicação organizacional nesse tipo de atividade, cada vez mais recorrente nas corporações comerciais e, também, nas organizações religiosas, uma vez que estão sujeitas ao mesmo escrutínio de sentidos no cotidiano de suas interações? 
Esses dois pontos merecem ser considerados e tornados objetos de reflexão para os gestores, não apenas da Igreja Adventista do Sétimo Dia, mas de organizações religiosas em geral face a uma vulnerabilidade maior hoje diante de tantos públicos em contato e com tantas possibilidades de se perceber a imagem corporativa.

O questionamento vale, ainda, na medida em que as soluções organizacionais, especificamente no caso de crises de imagem, parecem passar muito mais por decisões que envolvem diferentes áreas do conhecimento humano ou disciplinas distintas, frente à complexidade dos problemas apresentados e de sua extensão.

Não há efetivamente uma receita de bolo pronta para essa gestão, já que ela abrange, tanto o discurso da organização quanto a percepção criada pelos públicos e formação de um determinado tipo de imagem. O que se pode debater e discutir é, partindo desse artigo, a necessidade de começar a se enxergar a gestão profissional de crises de imagem como elemento que faz parte estratégica da comunicação organizacional.

\section{Referências}

A NOTÍCIA. Dez anos depois, caso Gabrielli continua sem solução em Joinville. Joinville, 1.05.2017. Disponível em http://anoticia.clicrbs.com.br/sc/geral/joinville/noticia/2017/05/dezanos-depois-caso-gabrielli-continua-sem-solucao-em-joinville-9783831.html. Acesso em 18.06.2017.

ARGENTI, Paul. Comunicação Empresarial - A construção da identidade, imagem e reputação. Rio de Janeiro: Elsevier, 2011.

BUENO, Wilson. Comunicação Empresarial: Política e Estratégias. São Paulo: Saraiva, 2009.

COOMBS, Timothy W. Ongoing crisis communication: planning, managing, and responding in: JORGE, Nuno da Silva. Reputação: um elemento diferenciador e protector face a crises organizacionais (dissertação de mestrado). Lisboa, 2010.

COSTA, Joan. Imagen Corporativa en el siglo XXI. Buenos Aires: La Crujía, 2009.

FORNI, J.J. Comunicação em tempos de crise. Entrevista à revista Organicom - Revista Brasileira de comunicação Organizacional e Relações semestre de 2007. São Paulo: ECA/USP, 2007.

IASBECK, Luiz Carlos. A Administração da Identidade - Um estudo semiótico da comunicação e da cultura nas organizações (tese de doutorado). São Paulo, 1997. 
Imagem e reputação na gestão da identidade organizacional. Organicom, Ano 4, Número 7, p. 87-97, $2^{\circ}$ semestre de 2007.

IASDCENTRALDEBRASÍLIA, Igreja Adventista Central de Brasília. Quem somos: missão e visão. Acesso em 10/10/2017. Disponível em: http://www.iasdcentraldebrasilia.com.br/quem-somos-2/.

JORGE, Nuno da Silva. Reputação: um elemento diferenciador e protector face a crises organizacionais (dissertação de mestrado). Lisboa, 2010.

NETO, Belmiro Ribeiro da Silva. Gestão e Comunicação de Risco e de Crises in: NETO, Belmiro Ribeiro da Silva (org.). Comunicação corporativa e reputação: construção e defesa da imagem favorável. São Paulo: Saraiva, 2010.

PEIRCE, Charles Sanders. Semiótica. São Paulo: Perspectiva, 2005.

SANTAELLA, Lúcia. O que é semiótica? São Paulo: Brasiliense, 1985.

TEIXEIRA, Patrícia. Caiu na rede. E agora? Gestão e gerenciamento de crises nas redes sociais. São Paulo: Évora, 2013.

THOMAZ, José Carlos \& BRITO, Eliane Pereira Zamith. Comunicação corporativa: contribuição para a reputação das organizações. Comunicação organizacional na perspectiva da complexidade. Revista Organicom, n. 7, 2007.

WEBER SHANDWICK. The company behind the brand ii: in goodness we trust. Estados Unidos, 15.02.2017. Disponível em

http://www.webershandwick.com/uploads/news/files/company-behind-the-brand-ingoodness-we-trust.pdf. Acesso em 18.06.2017. 